Check for updates

Cite this: RSC Adv., 2019, 9, 863

\title{
Graphene/Si Schottky solar cells: a review of recent advances and prospects
}

\author{
Xinyi Kong, Linrui Zhang, Beiyun Liu, Hongli Gao, Yongzhe Zhang, (DD Hui Yan \\ and Xuemei Song (D) *
}

Graphene has attracted tremendous interest due to its unique physical and chemical properties. The atomic thickness, high carrier mobility and transparency make graphene an ideal electrode material which can be applied to various optoelectronic devices such as solar cells, light-emitting diodes and photodetectors. In recent years, there has been a growing interest in developing graphene/silicon Schottky junction solar cells and the power conversion efficiency has reached up to $15.8 \%$ with an incredible speed. In this review, we introduce the structure and mechanism of graphene/silicon solar cells briefly, and then summarize several key strategies to improve the performance of the cells. Finally, the challenges and prospects of graphene/ silicon solar cells are discussed in the development of the devices in detail.

Received 27th September 2018 Accepted 12th December 2018

DOI: $10.1039 / \mathrm{c} 8 \mathrm{ra0} 8035 \mathrm{f}$

rsc.li/rsc-advances silicon substrate. ${ }^{6}$ Despite of the complicated processes, they are of high pollution and energy-consumption which is contradictory to the aim of clean energy. In addition, the high temperature processes also result in decrease of Si minority carrier life time, which greatly deteriorates the solar cell performance. ${ }^{7}$ Compared to the traditional solar cells, Schottky junction solar cells have the merits of easy fabrication and low cost, ${ }^{8}$ it can be formed by depositing metal film or transparency electrode on semiconductor wafer, two-dimensional materials have also been introduced as transparent electrodes in recent years.

\section{Graphene-Si Schottky junction solar cells}

Schottky junction solar cells, fabricated by directly depositing a thin layer of metal or transparency electrode on a moderate doped semiconductor wafer, are receiving much attention in photovoltaic field. ${ }^{9}$ Compared to the traditional $\mathrm{p}-\mathrm{n}$ junction solar cells, the Schottky junction solar cells have the merits of easy fabrication and low cost. ${ }^{8}$ However, the metal layer should be thick enough to form a junction in a conventional Schottky junction solar cell, which will have a negative effect on the absorption of the solar radiation. ${ }^{\mathbf{1 0}}$ Indium tin oxide (ITO), as an alternative for the metal layer, has been chosen by researchers. ${ }^{\mathbf{1 1}}$ However, the limited resource of indium will lead to high production cost, and the brittle nature of ITO will limit its application for flexible devices. ${ }^{12}$

Graphene, the model of two-dimensional material, was first fabricated by mechanical exfoliation out of graphite by Geim and Novoselov in 2004. ${ }^{13}$ As a single layer of carbon atoms packed together with hexagonal structure, ${ }^{\mathbf{1 4}}$ it is a promising material with many unique characteristics. The transparency 
can reach to $97.7 \%$ in the near-infrared and visible region, ${ }^{15,16}$ the excellent optical properties of graphene can effectively avoid the loss of photons. The carrier mobility achieves to $10^{4} \mathrm{~cm}^{2} \mathrm{v}^{-1}$ $\mathrm{s}^{-1}$ at room temperature, ${ }^{17,18}$ all the superior optical and electronic properties render graphene a promising transparent electrode in organic light-emitting diodes, ${ }^{19,20}$ sensors $^{21,22}$ and solar cells. ${ }^{23,24}$ Additionally, graphene is not only flexible but abundant in the globe, ${ }^{25,26}$ so it has drawn great attention to replace indium tin oxide (ITO) and fluorine tin oxide (FTO) for producing low-cost devices. ${ }^{27,28}$ Its tunable work function allows graphene to be served as either n-type or p-type electrodes. ${ }^{29-31}$ Moreover, graphene is generally superior in its great mechanical strength, ${ }^{32}$ environment stability, ${ }^{33}$ and crystalline quality in large-scale synthesis compare with other two-dimensional materials, such as $\mathrm{MoS}_{2}$, hexagonal boron nitride (h-BN) and so on. ${ }^{34,35}$

In consideration the excellent optical and electrical properties of graphene, there is a great interest in developing graphene/Si Schottky junction solar cells in recent years. In 2010, the first graphene/n-Si Schottky junction solar cell was reported by Zhu et al. ${ }^{23}$ They showed that graphene film can be combined with Si to form efficient solar cells. In this kind of solar cells, graphene not only acts as a transparency electrode, but also plays an important role in photo-carriers separation and transport. ${ }^{23}$

In this review, the structure and mechanism of the graphene/ Si solar cells are exhibited. Afterwards, several key ways which can enhance the power conversion efficiency (PCE) are introduced in detail. Lastly the challenges and prospects are discussed in the development of the devices, all of which may provide researchers a better understanding of the graphene/Si solar cells.

\section{Structure and mechanism of graphene/Si solar cells}

The structure of graphene/Si solar cells is illustrated in Fig. 1a. The $\mathrm{SiO}_{2}$ layer is wet-etched with pure or buffered HF solution from Si wafer to expose a square window which defines the active area of the solar cell. The front contact is prepared by photolithography and metal deposition, then single layer, bilayer or multilayer graphene is directly transferred onto the top of the patterned substrates via a solution method to create a conformal coating with the front contact and underlying n-Si. In such devices, a built-in electric field is established due to work function difference of the two materials, graphene and ntype $\mathrm{Si}$ adjust their Fermi lever to the common position (Fig. 1b). ${ }^{36,37}$ When incident light penetrate into the junction, the electron-hole pairs are created in $\mathrm{Si}$ and then carriers are separated by the built-in electric field. The electrons drift toward the n-type Si direction and holes drift to the graphene side, resulting in the output of current and power. In graphene/ Si solar cells, the built-in potential $\Phi_{\mathrm{SBH}}$ is determined by the difference between the work function of graphene $\Phi_{\mathrm{G}}$ and the electron affinity of $\mathrm{n}$-Si $\chi_{\mathrm{Si}} \cdot{ }^{38}$ Since the work function of graphene is tunable, we have more freedom in device design to optimize the separation and collection of the electrons and holes in graphene/Si solar cells, and result in larger potential drop across the depletion width, all of which can allow a more efficient collection of carriers.

Open-circuit voltage $\left(V_{\mathrm{OC}}\right)$, short-circuit current $\left(I_{\mathrm{SC}}\right)$, filling factor (FF) and PCE of the solar cells are the main parameters to evaluate the performance of solar cells. All of them can be obtained from light $J-V$ curves when the devices are tested with a solar simulator under AM 1.5 conditions. When the graphene/ $\mathrm{Si}$ solar cell is open-circuited, the separation of photongenerated carriers will create $V_{\mathrm{OC}}$. When the solar cell is shortcircuited, the extracted photogenerated carriers can transit through the external circuit, generating $I_{\mathrm{SC}}$. At $V=V_{\mathrm{OC}}$, these two currents will cancel each other and result in a zero net current. The PCE $(\eta)$ of a solar cell is defined as the incident power which is converted to electricity and it can be expressed as below:

$$
\eta=\frac{\max (I \times V)}{P_{\text {in }}}
$$

$\mathbf{a}$

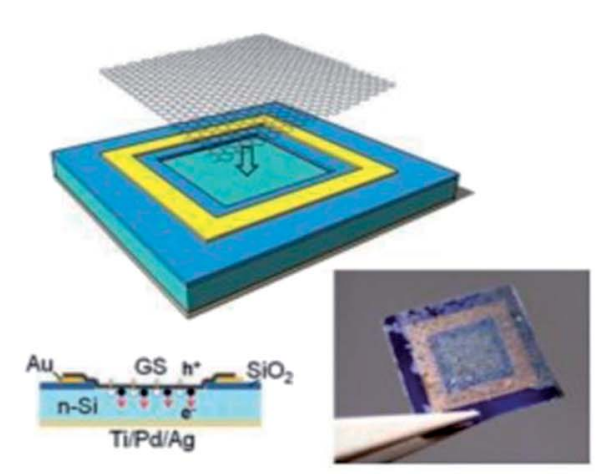

b

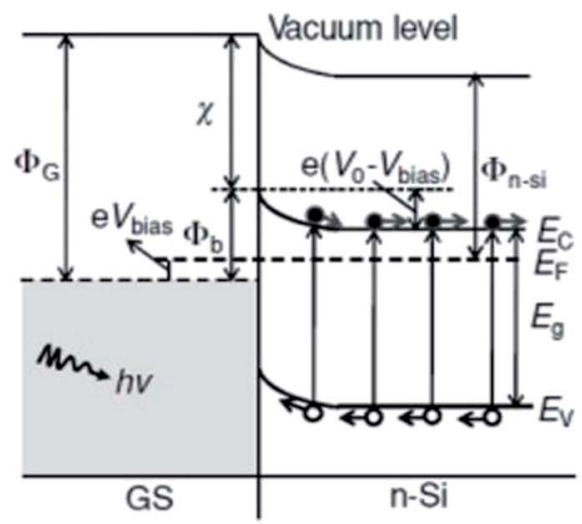

Fig. 1 Characterizations of the graphene/n-Si Schottky junction. (a) Schematic illustration of the device configuration. (b) Energy diagram of the forward-biased graphene/n-Si Schottky junction upon illumination. Reproduced from ${ }^{23}$ with permission from Wiley. 
where $P_{\text {in }}$ is the power of incident light. FF of a solar cell representing the characteristic of the maximum power of the devices under optimal load, which is always less than 1 . It can be defined as:

$$
\mathrm{FF}=\frac{V_{\mathrm{m}} I_{\mathrm{m}}}{V_{\mathrm{OC}} I_{\mathrm{SC}}}
$$

The non-linear dark $J-V$ characteristics of the graphene/Si solar cells can be described by the formula as follows: $:^{39}$

$$
J=J_{\mathrm{S}}\left[\exp \left(\frac{e V}{n k_{\mathrm{B}} T}\right)-1\right]
$$

where $J$ is the current density across the interface of graphene/ silicon, $J_{\mathrm{S}}$ is the reverse dark-saturation current density, $e$ is the elementary charge, $V$ is the applied voltage, $n$ is the diode ideality factor, $k_{\mathrm{B}}$ is the Boltzmann constant, $T$ is the absolute temperature. The ideality factor $n$ reflects the quality of the contact interface between graphene and silicon of Schottky junction and describes the carrier recombination of the interface, ${ }^{40} n$ and $J_{\mathrm{S}}$ of the solar cells can be obtained by fitting the $\ln J-V$ curve.

According to Schottky-Mott mode, the mental with work function $\left(\Phi_{\text {metal }}\right)$ higher than the electron affinity $\left(\chi_{\mathrm{e}}\right)$ of the a certain semiconductor can create a Schottky barrier height, ${ }^{41}$ $\Phi_{\mathrm{SBH}}=\Phi_{\text {metal }}-\chi_{\mathrm{e}}$, which is helpful to produce a relatively large built-in filed to block the recombination of holes and electrons. Similarly, the junction barrier height between graphene and silicon also observes the rules. The barrier height $\Phi_{\mathrm{SBH}}$ can be obtained by the thermal emission theory: ${ }^{\mathbf{4 2}}$

$$
J_{\mathrm{S}}=A^{*} T^{2} \exp \left(\frac{-e \Phi_{\mathrm{SBH}}}{k_{\mathrm{B}} T}\right)
$$

where $A^{*}$ is the effective Richardson constant $\left(252 \mathrm{~A} \mathrm{~cm}^{-2} \mathrm{~K}^{-2}\right.$ for $\mathrm{n}-\mathrm{Si}$ ). The barrier height $\Phi_{\mathrm{SBH}}$ is about $0.75 \mathrm{eV}$, namely the difference between $\Phi_{\mathrm{G}}$ and $\chi_{\mathrm{e}}\left(\Phi_{\mathrm{SBH}}=\Phi_{\mathrm{G}}-\chi_{\mathrm{e}}=4.8-4.05=0.75\right.$ $\mathrm{eV}){ }^{23}$

\section{The optimization of graphene/Si solar cells}

The PCE of the first graphene/Si solar cell is only about $1.5 \%$, far below the requirements for industrial application. ${ }^{23}$ The poor performance of the solar cells can be attributed to: (1) the pristine single-layer graphene has low work function $(\sim 4.4 \mathrm{eV})$ and large sheet resistance (a few kohms). ${ }^{20}$ The low work function can decrease the barrier height, which will lower the builtin electric field and prevent electron-hole pairs separating, ${ }^{43}$ while the large sheet resistance can lead to large series resistance. (2) The absorbed photon number is reduced by the planar Si wafers which is $30-40 \%$ for visible light $(350-800$ $\mathrm{nm}) .{ }^{44}$ After graphene/Si solar cells was reported in $2010,{ }^{23}$ lots of methods are developed to tune the work function and conductivity of graphene and the reflectance Si wafers, such as chemical doping, ${ }^{45-50}$ increasing layer number of graphene ${ }^{51,52}$ and introducing an interlayer, ${ }^{53-59}$ all of which can help to optimize the performance of solar cells significantly.

\subsection{Optimization of the work function and conductivity of graphene}

4.1.1 Doping of graphene. Doping of graphene can remarkably improve the performance of graphene/Si solar cells since it has been deemed to be the most effective way which would not only improve the electrical conductivity of graphene but also tune its work function. ${ }^{47}$ Up to now, different dopants such as $\mathrm{HNO}_{3}, \quad \mathrm{SOCl}_{2}$, and $\mathrm{H}_{2} \mathrm{O}_{2}, \mathrm{HCl}$, bis(trifluoromethanesulfonyl)amide (TFSA), $\mathrm{Au}$ or $\mathrm{Pt}$ nanoparticles have proved to effectively improve the performance of solar cells. ${ }^{45-50}$ Among them, $\mathrm{HNO}_{3}$ doping is deemed to be the most commonly used method. ${ }^{60}$ Feng et al. demonstrated that after immersing the device in $\mathrm{HNO}_{3}$ vapor for several seconds, (Fig. 2a and b). The PCE of the solar cell boosted from $2.9 \%$ to $4.35 \%$ under AM1.5 illumination with the $V_{\text {OC }}, J_{\text {SC }}$, FF increased to $495 \mathrm{mV}, 17.22 \mathrm{~mA} \mathrm{~cm}^{-2}$ and $51 \%$, respectively. ${ }^{47}$ The series resistance $\left(R_{\mathrm{s}}\right)$ of the solar cell also decreased from $6.11 \Omega \mathrm{cm}^{2}$ to $4.07 \Omega \mathrm{cm}^{2}$ after $\mathrm{HNO}_{3}$ treatment. They attributed the obvious performance enhancement to the heavy p-type doping by $\mathrm{HNO}_{3}$, and the $V_{\mathrm{OC}}$ increased after treatment due to the work function upshift of graphene (Fig. 2e); the increase in $J_{\mathrm{SC}}$, as well as the decrease in $R_{\mathrm{s}}$, demonstrated an increase in graphene conductivity.

Similar to $\mathrm{HNO}_{3}, \mathrm{SOCl}_{2}$ and $\mathrm{H}_{2} \mathrm{O}_{2}$ can also lead to the improved performance of solar cells. Four volatile oxidants $\mathrm{HNO}_{3}, \mathrm{SOCl}_{2}, \mathrm{HCl}$, and $\mathrm{H}_{2} \mathrm{O}_{2}$ were employed by Cui et al. to dope the graphene films in graphene/Si solar cells. ${ }^{48}$ They placed the assembled graphene/Si solar cells above a vial containing $\mathrm{HNO}_{3}$ (65 wt\%), $\mathrm{SOCl}_{2}$ (99.5 wt\%), $\mathrm{HCl}$ (36 wt\%), or $\mathrm{H}_{2} \mathrm{O}_{2}(30 \mathrm{wt} \%)$ for $1 \mathrm{~min}$. It has been shown that the PCE could be remarkably enhanced after being treated by either of the four volatile oxidants. The PCE enhancement of the volatile oxidanttreated cells are primarily contributed by the improvement in FF and $V_{\text {OC }}$. Among all the four volatile oxidants, the PCE enhanced by $\mathrm{SOCl}_{2}$ doping showed the best improvement (Fig. 2d). A solar cell with an initial PCE of $2.58 \%\left(V_{\mathrm{OC}}=\right.$ $412.10 \mathrm{mV}, J_{\mathrm{SC}}=17.65 \mathrm{~mA} \mathrm{~cm}{ }^{-2}, \mathrm{FF}=35.42 \%$ ) could be increased to $5.95 \%\left(V_{\mathrm{OC}}=547.78 \mathrm{mV}, J_{\mathrm{SC}}=17.92 \mathrm{~mA} \mathrm{~cm}^{-2}, \mathrm{FF}\right.$ $=60.64 \%$ ) after $\mathrm{SOCl}_{2}$ doping treatment (Fig. 2c). They also investigated the stability of the volatile oxidant-treated cells by keeping them in ambient conditions for 8 days. Due to the volatilization of the volatile oxidant, the PCE of the volatile oxidant treated cells decreased with storage time in the air, and the results also showed that solar cells treated by $\mathrm{SOCl}_{2}$ and $\mathrm{HCl}$ have relatively better stability than that of $\mathrm{HNO}_{3}$ and $\mathrm{H}_{2} \mathrm{O}_{2}$ ones.

In addition to the volatile oxidants, doping with organic polymer dopant TFSA is also an effect way to improve the performance of graphene/Si solar cells. Miao et al. reported that TFSA could increase the conductivity of graphene significantly by p-doping. ${ }^{45}$ They demonstrated that the PCE of the device doping with TFSA was increased to $8.6 \%$ from the original (undoped) PCE of $1.9 \%$ and the $J_{\mathrm{SC}}$ increased from 14.2 to 25.3 $\mathrm{mA} \mathrm{cm}{ }^{-2}, V_{\text {OC }}$ increased from 0.43 to $0.54 \mathrm{~V}$, respectively. Fig. 3a and $\mathrm{b}$ notes that $\mathrm{p}$-type doping can increase the work function of graphene, which will lead to an improvement of $\Phi_{\mathrm{SBH}}$, creating a larger potential drop across the depletion width and 
a

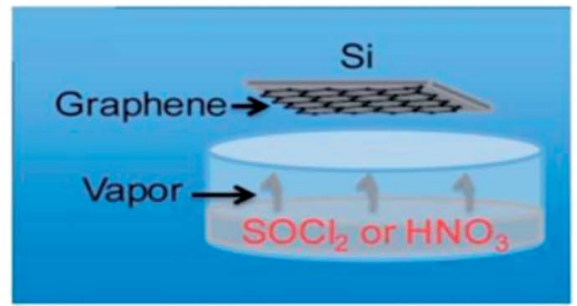

c

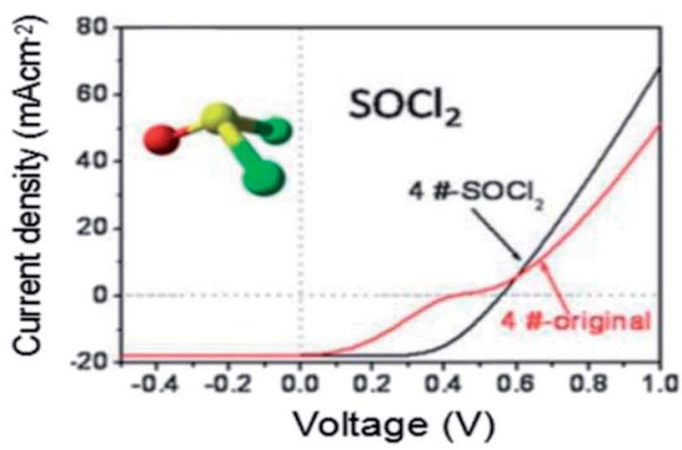

e

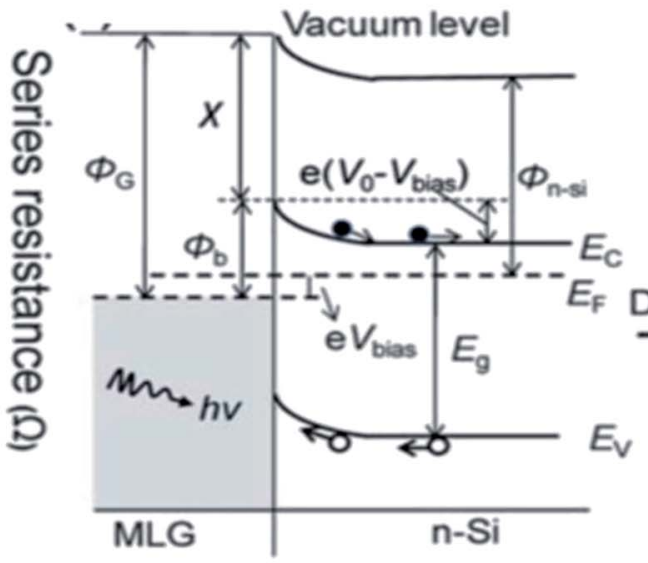

b

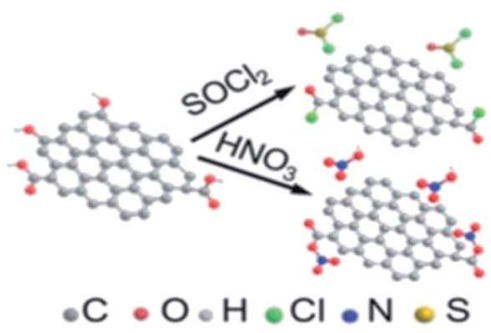

d

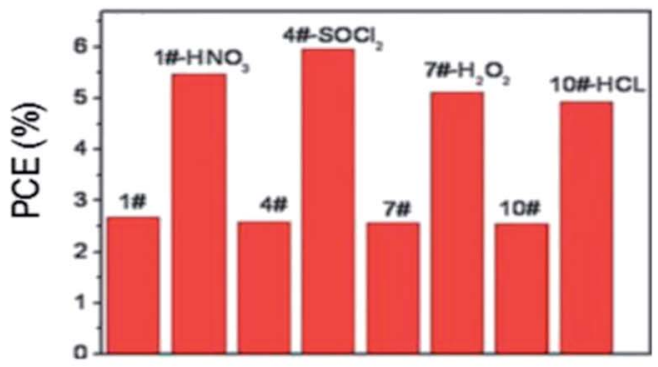

Solar cells

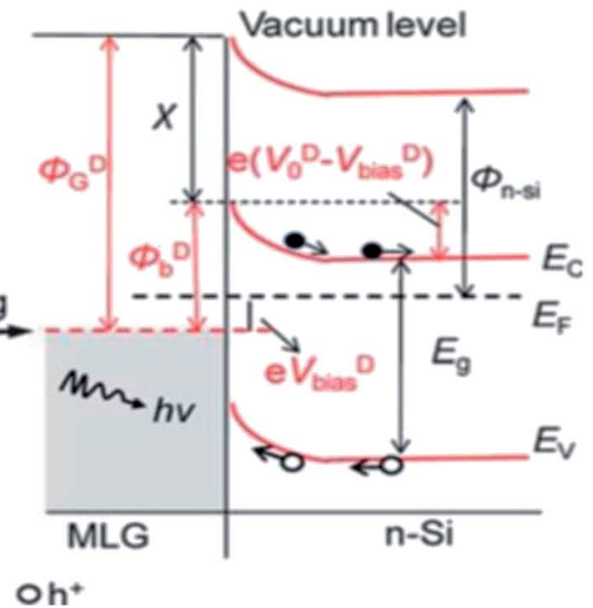

Fig. 2 (a) Schematic illustration of the vapor doping process. The device was exposed to the $\mathrm{SOCl}_{2}$ (or $\mathrm{HNO}_{3}$ ) vapor for a few seconds and chlorine (nitrate) anions were doped on the films. (b) Scheme of the doping mechanism. (c) J-V characteristics of the solar cell before (red curve) and after (black) infiltration of dilute $\mathrm{SOCl}_{2}$. (d) Light J-V curves and PCE of solar cells before and after volatile oxidant treatment. (e) The band schematics at the MLG/Si interface before and after doping. Reproduced from ${ }^{46}$ and $^{48}$ with permission from The Royal Society of Chemistry.

allowing a more efficient of electrons and holes separation and collection. Due to the p-type doping effect, the enhanced work function of the graphene therefore leads to an decrease the sheet resistance and improvement of the barrier height in graphene/n-Si junction. ${ }^{61}$ The electrical and optical properties of monolayer graphene after TFSA doping were also investigated by Lai et $a l .{ }^{62}$ The results showed that doping with TFSA can efficiently lower the sheet resistance of graphene because the resistance decreased from $1200 \Omega \mathrm{cm}^{2}$ to $300 \Omega \mathrm{cm}^{2}$ rapidly, and the UV-visible transmittance spectra also presented that the TFSA preserved graphene's optical properties without any significant reduction that single layer graphene still remained extremely high transmittance after chemical doping (Fig. 3c), all of which make it possible to fabricate graphene-Si solar cells with superior electrical-optical properties.

In addition to volatile oxidants and TFSA, several groups also attempted to improve the PCE of graphene/Si solar cells by metal nanoparticles (NPs) such as $\mathrm{Au}, \mathrm{Pt}^{49,60,63,64}$ Introducing nanoparticles not only improves the work function and decreases the sheet resistance of graphene, but can possibly increase the light absorption and PCE of the devices. ${ }^{65}$ For example, Kim and the coworkers deposited Au layer on graphene by radio frequency sputtering and annealed in nitrogen atmosphere to gain Au NP-doped graphene-Si solar cells. ${ }^{64}$ As 
a

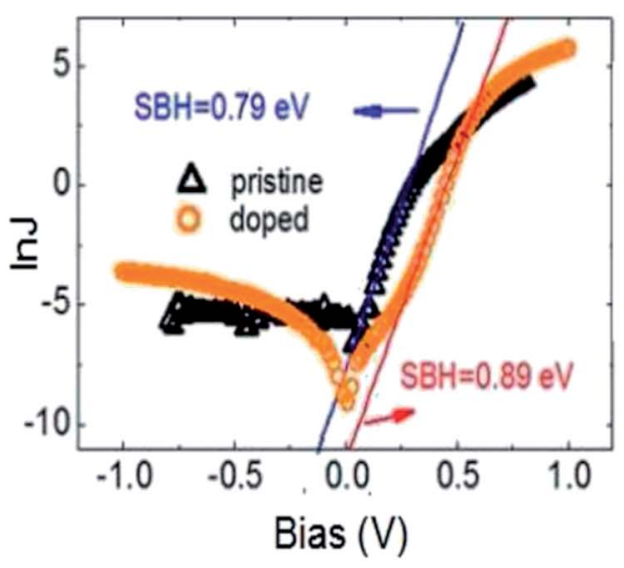

b

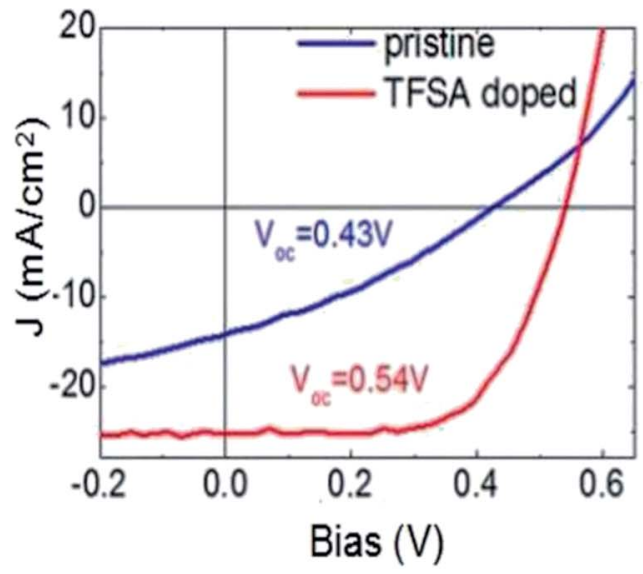

C

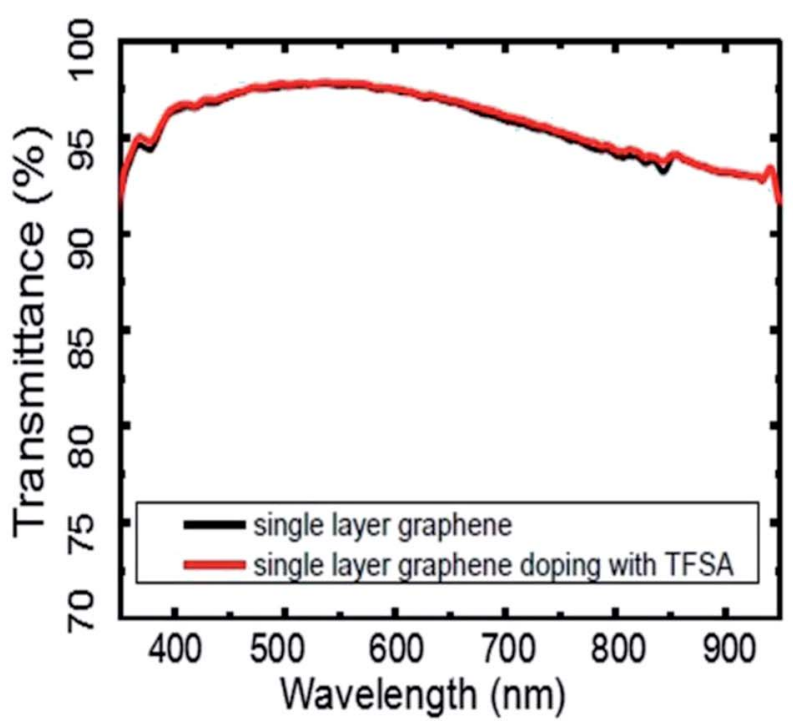

Fig. 3 (a) J-V characteristics in the semi-logarithmic scale. (b) Amplified J-V characteristics of graphene/n-Si diodes. (c) The transmittance spectra of graphene. (a and b) Reproduced from ${ }^{45}$ with permission from The American Chemical Society (c) reproduced from ${ }^{62}$ with permission from IEEE Xplore.

displayed in Fig. 4a, the discrete spherical nanoparticles are uniformly distributed on the graphene surface. In the XPS spectra, shown in Fig. 4b, indicating Au NPs are successfully doped into graphene. The PCE was increased from $3.52 \%$ to $7.51 \%$ after doping of Au nanoparticles. It was further enhanced to $10.69 \%$ by co-doping it with TFSA.

Liu et al. also reported a structure of Au nanoparticles/ graphene/Si solar cells by incorporating Au nanoparticles onto the graphene layers to improve the device performance. ${ }^{49}$ Different with Kim et al., they deposited Au thin layer with various thickness onto the monolayer graphene (MLG) and fewlayer graphene (FLG), then annealed under nitrogen flow to gain Au NPs with different sizes. Fig. 4c showing that the $V_{\mathrm{OC}}$ increases monotonically with Au thickness for the two batches of devices, and the $V_{\mathrm{OC}}$ of the solar cells with multilayer graphene $(0.40-0.45 \mathrm{~V})$ is much higher than that of single layer devices $(0.26-0.42 \mathrm{~V})$, which is in good agreement with the previous works in which the $V_{\mathrm{OC}}$ difference is attributed to the increased work function of graphene with more layers. ${ }^{51}$ Unlike $V_{\mathrm{OC}}$, the value of $J_{\mathrm{SC}}$ is found to exhibit a first-rise then decrease behavior of which the critical Au thickness was $9 \mathrm{~nm}$, and FF showed a similar tendency as $J_{\mathrm{SC}}$ (Fig. $4 \mathrm{~d}$ ). Due to the increased $V_{\mathrm{OC}}, J_{\mathrm{SC}}$, and $\mathrm{FF}$ after incorporating $\mathrm{Au}$ nanoparticles, a maximum PCE of $7.34 \%$ has been obtained for the $\mathrm{Au}$ nanoparticles/multilayer graphene/Si cells when the Au thickness is $9 \mathrm{~nm}$, which is more than three times of the original value (Fig. 4e). In this work, Au-doping gives rise to an enhanced built-in electric field and thus an improved $V_{\mathrm{OC}}$ in the solar cell, meanwhile, the enhanced electrical conductivity of graphene and the reduced $R_{\mathrm{S}}$ of cell lead to a higher $\mathrm{FF}$ and $J_{\mathrm{SC}}$. This work provides a route for developing stable, and highly efficient graphene/Si solar cells. 
a

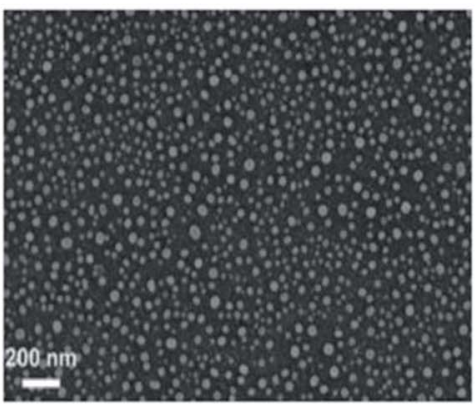

C

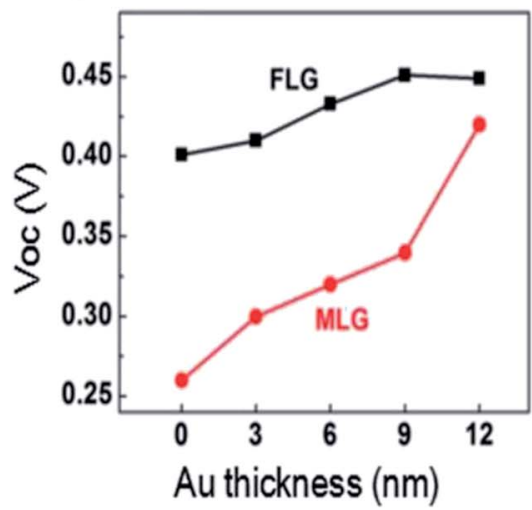

e

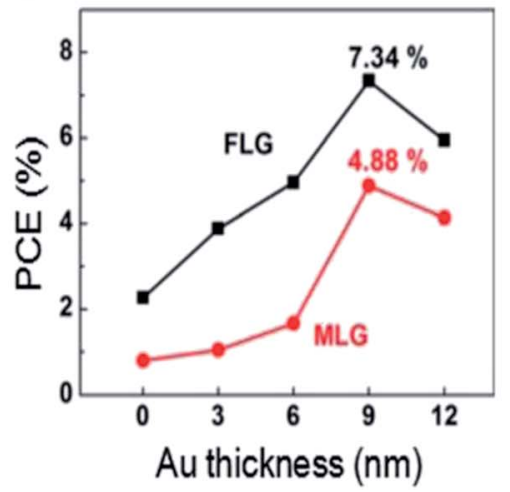

b

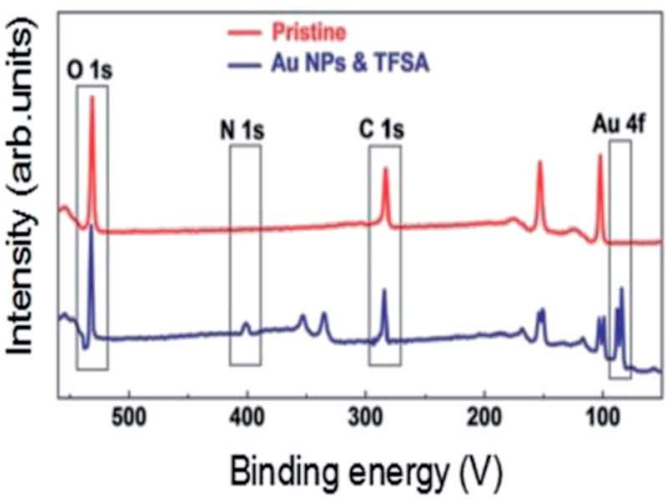

d

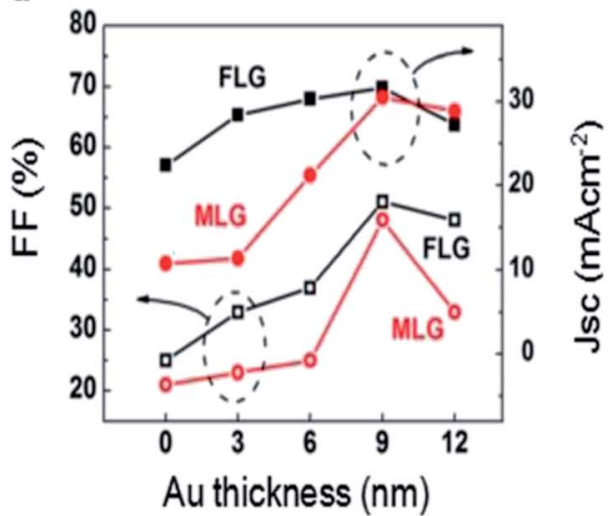

f

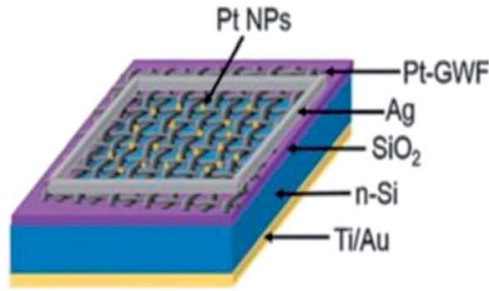

Fig. 4 (a) SEM image of the surface of Au NPs/TFSA-doped graphene. The scale bar indicates $200 \mathrm{~nm}$. (b) XPS spectra of graphene layers with and without Au NPs/TFSA dopants. (c) $V_{O C}$, (d) $J_{S C}$ and FF, (e) PCE as functions of the Au thickness for both Au NPs/MLG/Si and Au NPs/FLG/Si solar cells. (f) Schematic diagrams of Pt-GWF/n-Si solar cell. (a and b) Reproduced from ${ }^{64}$ with permission from The Royal Society of Chemistry. (c-e) Reproduced from ${ }^{60}$ with permission from American Institute of Physics. (f) Reproduced from ${ }^{63}$ with permission from The Royal Society of Chemistry

Kang et al. developed an effective and practical method to deposit Pt nanoparticles on graphene woven fabrics (GWF) to improve the performance of graphene/silicon solar cells. ${ }^{63}$ (Fig. 4f) The deposition of Pt NPs increased the work function of GWF and also reduced the sheet resistance of GWF. The increased work function of GWF resulted in an enhanced builtin electric field and thus an improved $V_{\mathrm{OC}}$, whereas the enhanced conductivity led to a higher $J_{\mathrm{sc}}$, thereby improving the PCE of graphene/silicon solar cells. To further enhance the PCE of the solar cells, they also coated solid electrolyte $\left(\mathrm{HNO}_{3}+\right.$ PVA) onto the Pt NPs-GWF/n-Si solar cells which serves as photoelectron chemical channel, and the PCE was improved to $10.02 \%$. In comparison, the efficiency of the solar cell that was only coated with solid electrolyte (without Pt NPs deposition) was 7.51\%. The results suggest that the deposition of Pt NPs can improve the performance of the GWF/n-Si solar cells significantly. But it is worth noting that $\mathrm{Pt}$ is expensive compared with other metals, so it is necessary to find cheaper metal nanoparticles that can enhance the efficiency of graphene/Si solar cells in the future.

4.1.2 Controlling the layer number of graphene. While chemical doping is effective to the performance of the 
graphene/Si solar cells, it was found that the layer number of graphene also play a critical role in determining the PCE of solar cells.

The effect of the number of graphene layers on the performance of graphene/n-Si solar cells were investigated by Li et al. ${ }^{\mathbf{1 1}}$ They found that the $V_{\text {OC }}$ improved monotonically when the layer number of graphene increased (Fig. 5b). The reason is that the graphene work function could be tuned by its layer number, leading to improved barrier height of graphene/n-Si Schottky junction. Fig. 5 shows that with increasing graphene layer number, $J_{\mathrm{SC}}$ first linear increases when the layer number of graphene less than 4 , and then decreases when it further increases. They explained that the sheet resistance $\left(R_{\mathrm{S}}\right)$ decreases when the layer number is less than 4 , and then it has an opposite trend when the layer number more than 4. In addition, with the increase of layer number, the transmission of graphene reduced. In consideration of the sheet resistance and the transmittance, the 4-layer graphene solar cells exhibit the best performance.

Ihm et al. reported that the layer number-dependent trend is reversed for graphene/p-Si solar cells.. ${ }^{52}$ They found that $V_{\mathrm{OC}}$ decreased as the layer number of graphene increased. Similar in graphene/n-Si junction solar cells, when the layers increase, the work functions of graphene shows a sequential increase accordingly. And in the graphene/p-Si cell, $\Phi_{\mathrm{B}}=\chi_{\mathrm{Si}}-\Phi_{\mathrm{G}}$, so the barrier height of graphene/p-Si reduces, while improves that of graphene/n-Si junction solar cells. Jiao et al. fabricated PMMA/ bilayer graphene/CNWs-Si solar cell with a maximum PCE of $8.9 \%{ }^{66}$ A PMMA/few-layer graphene could be achieved by a layerby-layer (LBL) transfer method ${ }^{67,68}$ and poly(methylmethacrylate) (PMMA) film was kept after transferring graphene, serving as an efficient antireflection layer. As the layer number of graphene increased from 1 to 4 , the transmittance decreased from $96 \%$ to $87 \%$ in the visible range, while the $R_{\mathrm{S}}$ declined from 458 to $183 \Omega$ $\mathrm{cm}^{2}$. When the $R_{\mathrm{S}}\left(337 \Omega \mathrm{cm}^{2}\right)$ and transmittance $(94.5 \%$ at 550 $\mathrm{nm}$ ) had the best tradeoff with 2 layers, the optimal PCE of $8.9 \%$ was attained with $J_{\mathrm{SC}}, V_{\mathrm{OC}}$ and $\mathrm{FF}$ values of $29.1 \mathrm{~mA} \mathrm{~cm}^{-2}, 0.44 \mathrm{~V}$, and $69.8 \%$, respectively. When the layer number increased to 4 , the FF improved to $71.8 \%$ due to low $R_{\mathrm{S}}$, and the $J_{\mathrm{SC}}$ decreased to $25.1 \mathrm{~mA} \mathrm{~cm}^{-2}$ as a result of low transmittance, the efficiency declined to $7.6 \%$ (Table 1 ).

\subsection{Optimization of the reflectivity of silicon}

4.2.1 Nano- and microstructures for light trapping. Because of its high reflection, the planar Si surface has a high absorption loss about $30-40 \%$ in the visible range. ${ }^{69}$ In order to enhance the light harvesting, the silicon wafers have been engineered to different nano- or microstructures, such as pyramids, ${ }^{70,71}$ nanowires, ${ }^{72,73}$ nanopillars ${ }^{74-76}$ and so forth. The use of Si nano- or microstructures can significantly enhance light harvesting capability because of the strong light trapping effect which suppresses the reflection of the junction surface in the visible and near-infrared region, and can also achieve higher charge-collection efficiency. ${ }^{77,78}$ Therefore, it provides a potential route to fabricate high-efficiency graphene/Si solar cells based on Si nano- or microstructures. In recent years, nano- or microstructures to improve PCE of this kind of solar cells have been studied widely. For example, Fan et al. prepared silicon nanowire (SiNW) arrays by a silver-assisted etching method, ${ }^{79,80}$ and then transferred the graphene film directly on the n-silicon nanowire (SiNW) arrays. ${ }^{81}$ It is clearly shown in Fig. $6 \mathrm{a}$ and $\mathrm{b}$ that the SiNWs impart a significant reduction of

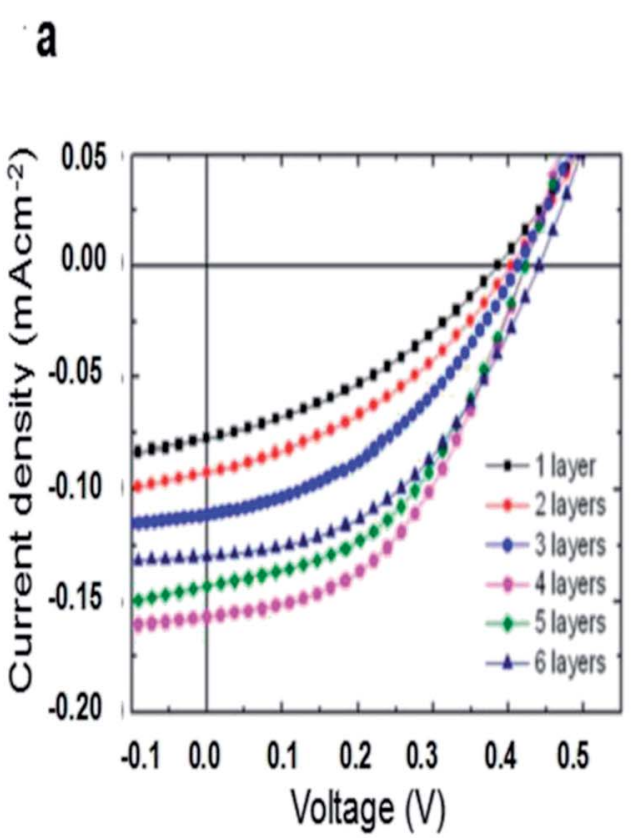

\section{(1)}

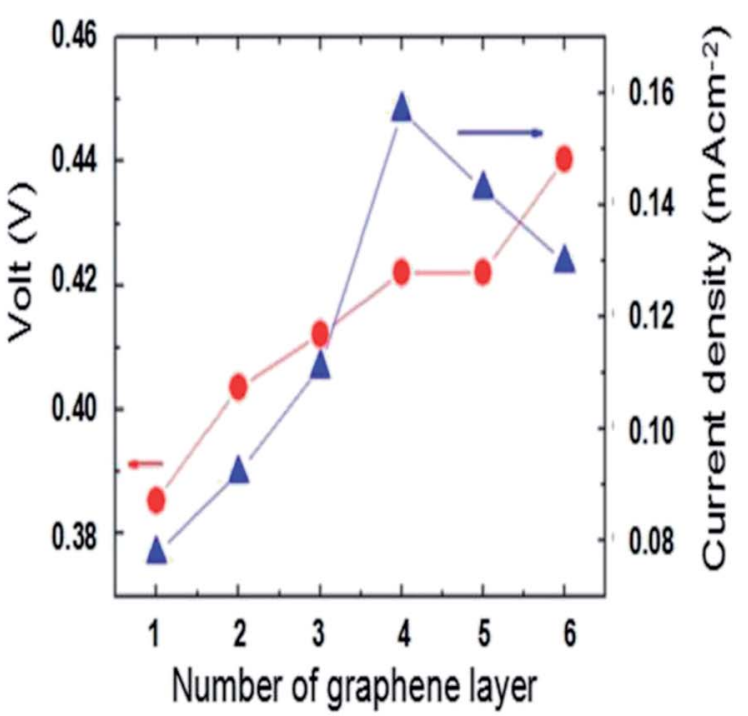

Fig. 5 (a) Current-voltage curves of solar cells based on graphene with 1, 2, 3, 4, 5, and 6 layers under illumination of $730 \mathrm{~nm} \mathrm{LED} \mathrm{(2} \mathrm{mW} \mathrm{cm}^{-2}$ ). (b) The open-circuit voltage and short-circuit current of solar cells measured as functions of the number of graphene layers. (a and b) Reproduced from ${ }^{51}$ with permission from American Institute of Physics. 
Table 1 Summary of engineering strategies and corresponding PCE values of the graphene/silicon Schottky solar cells studied by different research groups over the last ten years to date

\begin{tabular}{|c|c|c|c|c|}
\hline Method & Cell structure & PCE (\%) & Year & Ref. \\
\hline Original & Graphene/n-Si & 1.65 & 2010 & 23 \\
\hline \multirow[t]{2}{*}{ Chemical doping } & $\mathrm{HNO}_{3} /$ graphene/n-Si & 4.35 & 2011 & 47 \\
\hline & TFSA/graphene/n-Si & 8.6 & 2012 & 45 \\
\hline \multirow[t]{2}{*}{ Nanoparticle doping } & Au NPs/graphene/n-Si & 7.34 & 2014 & 49 \\
\hline & Pt NPs/GWF/n-Si & 10.02 & 2016 & 63 \\
\hline & $\mathrm{HNO}_{3} /$ graphene/SiPA & 3.55 & 2011 & 75 \\
\hline & $\mathrm{AuCl}_{3} /$ graphene/SiHA & 10.4 & 2013 & 84 \\
\hline \multirow[t]{4}{*}{ Antireflection layer } & $\mathrm{HNO}_{3} / \mathrm{TiO}_{2} /$ graphene/n-Si & 14.5 & 2013 & 44 \\
\hline & PMMA/bilayer graphene/CNWs/Si & 8.9 & 2016 & 66 \\
\hline & $\mathrm{HNO}_{3} / \mathrm{PMMA} /$ graphene/n-Si & 13.34 & 2016 & 85 \\
\hline & $\mathrm{MgF}_{2} / \mathrm{ZnS} /$ graphene/n-Si & 14.6 & 2018 & 87 \\
\hline
\end{tabular}

the reflectance. Upon illumination, the graphene/SiNW device displayed fairly good photovoltaic response, achieving a PCE of

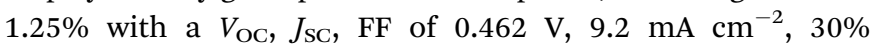
respectively. It can mainly attribute to two reasons. First, the SiNWs provide direct and fast pathway to increase the electricalhole collection and transport. Second, the SiNWs can improve light absorption and suppress the reflection of the junction surface in the visible and near-infrared region. Then $\mathrm{SOCl}_{2}$ vapor was used to dope the graphene film to further improve the PCE of the solar cells to $2.86 \%$. Feng et al. introduced pillararray-patterned silicon (SiPA) by photolithography and inductive couple plasma (ICP) etching ${ }^{82,83}$ to enhance the light harvesting of the solar cells, showing energy conversion efficiencies of $1.96 \% .^{75}$ Then $\mathrm{HNO}_{3}$ was used to dope graphene film and the energy conversion efficiency of graphene/SiPA Schottky solar cell improves to $3.55 \%$. Xie et al. demonstrated the construction of graphene/micro-hole array (SiHA) devices with enhanced performance and stability (Fig. $6 \mathrm{c}$ and d). ${ }^{84}$ They fabricated micro-hole array with a smooth surface via photolithography and RIE (reaction ion etching) possesses, and by controlling the etching time, the depth of the holes can be adjusted to tune the light harvesting of the SiHA. The light harvest capability of the solar cells were improved significantly when the hole depth increase to $12.8 \mathrm{~mm}$ and the maximum PCE was improved to $10.4 \%$ when combined the micro-hole array with $\mathrm{AuCl}_{3}$ doping. The promotion of the $J_{\mathrm{SC}}$ and $\mathrm{EQE}$ (external quantum efficiency) can be ascribed to the enhanced optical absorption of the SiHA with deeper holes (Fig. 6e and f). Additionally, the device showed remarkable stability and exhibited a high performance even storing in air for about 3 months. In view of the stability, nano- or microstructures can be a feasible technique for high efficiency graphene/Si solar cells.

4.2.2 Anti-reflection coating. In addition to the nano- or microstructures can reduce the high reflectance of planar $\mathrm{Si}$, some anti-reflection coating of transparent materials such as $\mathrm{TiO}_{2}{ }^{44}{ }^{4 M M A}{ }^{66,85} \mathrm{PDMS}^{86}{ }^{86} \mathrm{MgF}_{2} / \mathrm{ZnS}^{87,88}$ are also options to decrease the optical reflectivity of the solar cells. The antireflection effect is obtained when a suitable refractive index and film thickness are chosen. ${ }^{44}$ The antireflection layer is transparent to visible light and the refractive index $\left(n_{\mathrm{ARC}}\right)$ is between $\operatorname{Si}\left(n_{\mathrm{Si}} \approx 4\right)$ and air $\left(n_{\text {air }} \approx 1\right)$ approximately correlated by $n_{\mathrm{ARC}}=$ $\left(n_{\mathrm{Si}} n_{\text {air }}\right)^{1 / 2},{ }^{89}$ serves as a planar antireflection layer to suppress reflected light from polished Si surface. On the other hand, the thickness of the antireflection layer should correspond to the range of visible light according to $d=\lambda / 4 n_{\mathrm{ARC}},{ }^{90}$ thus it could serve as an effective antireflection layer.

Shi et al. introduced $\mathrm{TiO}_{2}$ as an antireflection layer, the structure can be illustrated as sandwich structure with $\mathrm{TiO}_{2}$ layer on the top, graphene in the middle, n-Si substrate at the bottom (Fig. 7a). ${ }^{44}$ The efficiency of the control cell without $\mathrm{TiO}_{2}$ antireflection layer is $8.9 \%$ after $\mathrm{HNO}_{3}$ doping. Then $\mathrm{TiO}_{2}$ colloidal solution was spin-coated on the window of graphene/Si solar cells to form a smooth and thin film. After coating $\mathrm{TiO}_{2}$, the reflectance was lowered to about $10 \%$ in the visible region (500-800 $\mathrm{nm})$. Consequently, the $J_{\mathrm{SC}}$ was increased significantly by $30 \%$ (from 23.9 to $32.5 \mathrm{~mA} \mathrm{~cm}{ }^{-2}$ ). The resulting $\mathrm{HNO}_{3}$ doped-TiO ${ }_{2}^{-}$ graphene-Si cell showed a $V_{\mathrm{OC}}$ of $0.60 \mathrm{~V}$, a FF of $73 \%$, and an efficiency of $14.1 \%$ (Fig. 7c). Here, $\mathrm{HNO}_{3}$ doping mainly improve the $V_{\mathrm{OC}}$ and $\mathrm{FF}$, while $\mathrm{TiO}_{2}$ coating significantly enhance the $J_{\mathrm{SC}}$. After optimized with both routes, the power conversion efficiency of both of graphene/Si solar cell reached $14.1 \%$. The device stability was studied after storing the solar cell for about 20 days in the ambient air. The results showed that the $J_{\mathrm{SC}}$ remained unchanged, $V_{\mathrm{OC}}$ dropped from 0.60 to $0.45 \mathrm{~V}$ and the $\mathrm{FF}$ reduced from $73 \%$ to $45 \%$, resulting in a degradation of cell efficiency (from $14.1 \%$ to $6.5 \%$ ). So it can be deduced that doping by volatile acid is indeed not stable and cell degradation occurs after loss of acid and doping effect. However, the antireflection effect by $\mathrm{TiO}_{2}$ coating was excellent since the $J_{\mathrm{SC}}$ remained unchanged about $32 \mathrm{~mA} \mathrm{~cm}^{-2}$ during the storage period. After that, they treated it by $\mathrm{HNO}_{3}$ vapor again, the $V_{\mathrm{OC}}$ returned from 0.45 to 
a

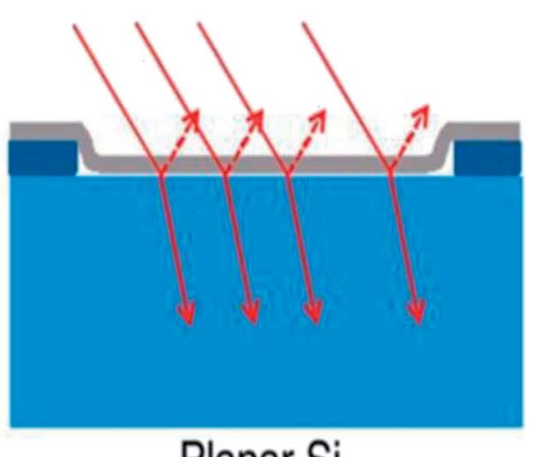

Planar Si

C

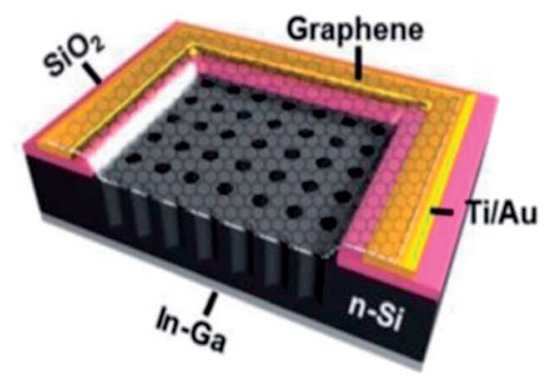

e

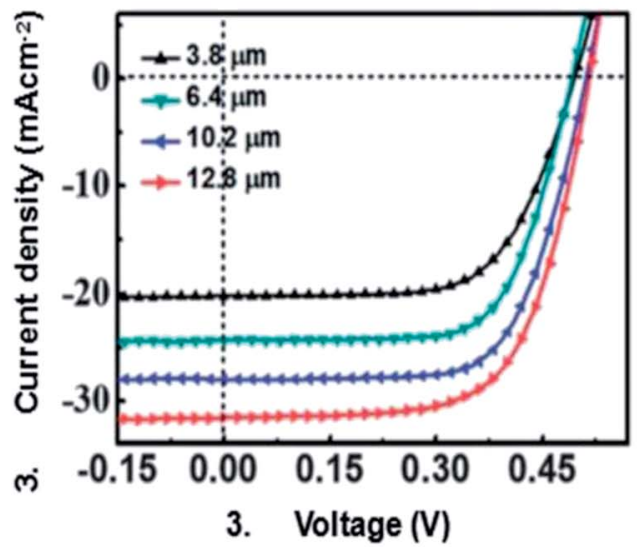

b

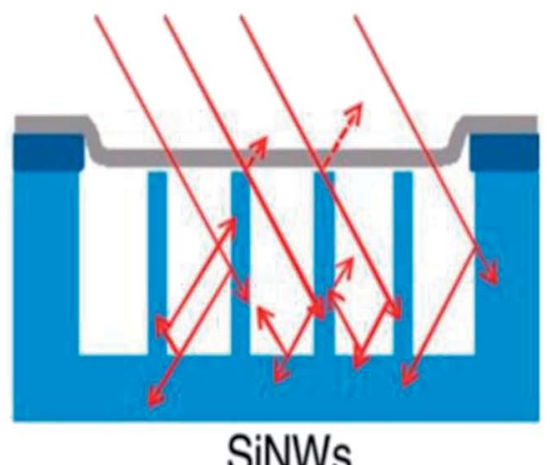

d

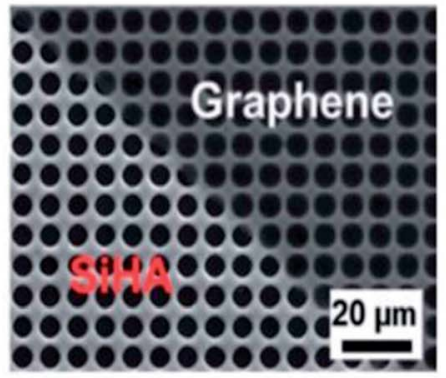

f

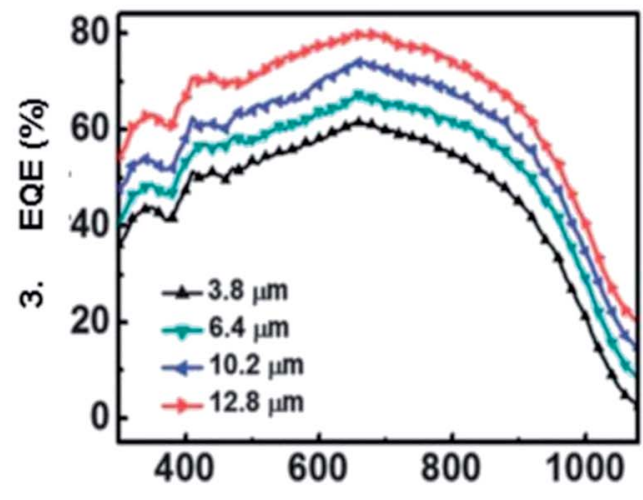

3. Wavelength $(\mathrm{nm})$

Fig. 6 Schematics diagrams of (a) graphene/planar Si and (b) graphene/SiNW junctions. (c) Schematic illustration of the graphene/SiHA Schottky junction solar cell. (d) Top-view SEM image of the graphene/SiHA device. (e) Photovoltaic characteristics and (f) EQE spectra of the graphene/ $\mathrm{SiHA}$ Schottky junction solar cells with various hole depths. ( $a$ and b) Reproduced from ${ }^{81}$ with permission from The American Chemical Society. (c-f) Reproduced from ${ }^{84}$ with permission from The Royal Society of Chemistry.

$0.6 \mathrm{~V}, \mathrm{FF}$ to $72 \%$. The efficiency of the re-doping solar cell can recover to $14.5 \%$, slightly higher than that before.

Gan et al. demonstrated a novel way of PMMA film as an antireflection layer on a graphene/silicon solar cell. ${ }^{85}$ Traditionally, PMMA protective coating was regarded as a protection layer during graphene transfer process, and is usually removed after transfer process. ${ }^{\mathbf{9 1}, \mathbf{9 2}}$ In this work, the PMMA was remained on the graphene film acting as an anti-reflection layer. And the Fig. $7 \mathrm{~d}$ shows that the transmittance at $550 \mathrm{~nm}$ measured was
96.0\% with PMMA coatings. With the PMMA-coating and $\mathrm{HNO}_{3}$ doping, the PCE reached up to $13.34 \%$. They also compared the antireflection effect of $\mathrm{TiO}_{2}$ with that of PMMA. The result showed that the efficiency of $\mathrm{TiO}_{2}$-coated graphene/Si solar cells are significantly inferior to those of PMMA-coated graphene/Si solar cells.

Ding et al. fabricated multi-color graphene/Si solar cells by taking advantage of the combination of $\mathrm{MgF}_{2} / \mathrm{ZnS}$ antireflection coating and graphene (Fig. 7b). ${ }^{87} \mathrm{ZnS}$ owns the 
a
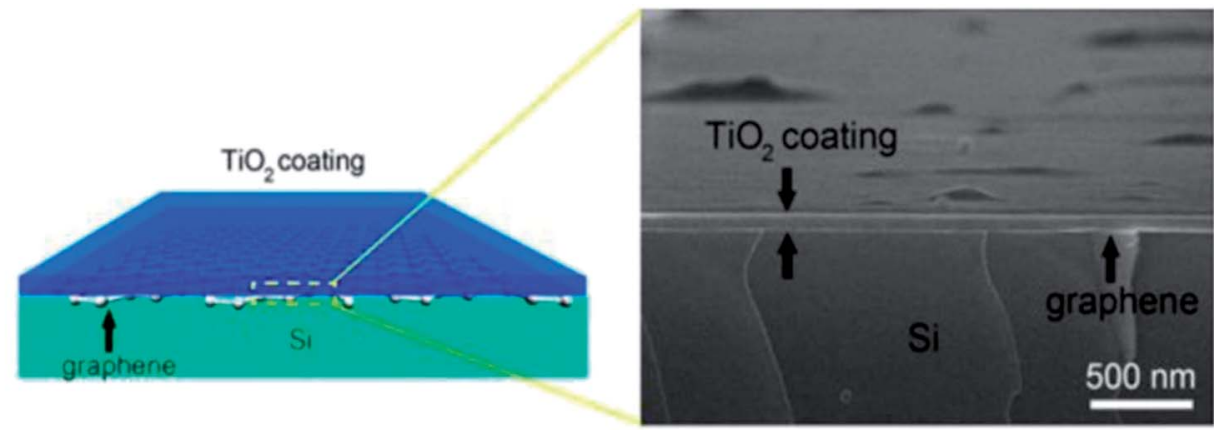

b

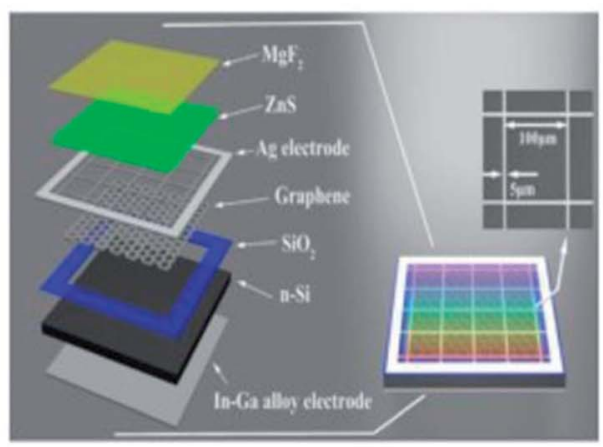

d

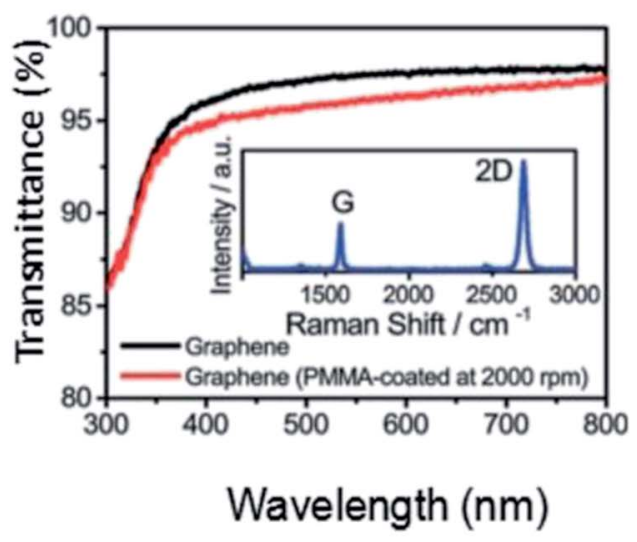

c

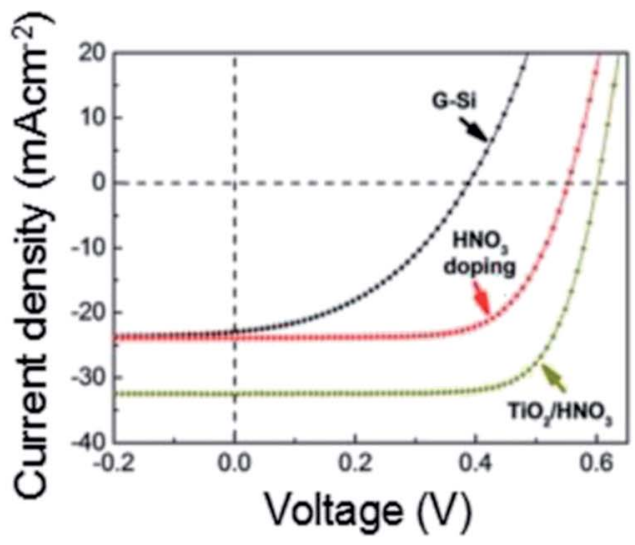

e

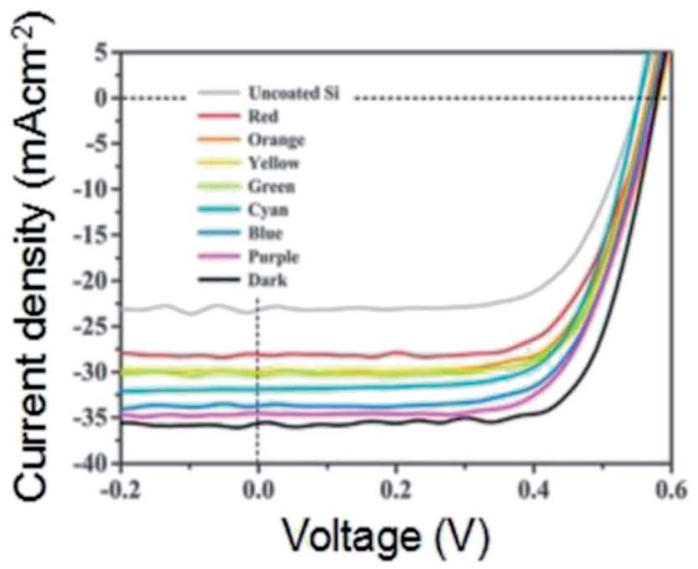

Fig. 7 (a) Illustration of the $\mathrm{TiO}_{2} /$ graphene/Si structure (left) and cross-sectional SEM image showing a uniform $\mathrm{TiO}_{2}$ coating (thickness of $\sim 65$ $\mathrm{nm}$ ) on top of the graphene-Si cell. (b) Schematic illustration of color graphene/Si heterojunction solar cells with double layer-MgF $/ 2 \mathrm{ZS}$ films. Inset shows the SEM image of the Ag grid mesh. (c) J-V characteristics of an as fabricated graphene-Si solar cell, after $\mathrm{HNO}_{3}$ vapor doping, and after $\mathrm{TiO}_{2}$ coating (combined with $\mathrm{HNO}_{3}$ doping), respectively. (d) Transmittance spectra of PMMA-removed and PMMA-coated (2000 rpm) graphene. The inset is a typical Raman spectrum of graphene on $\mathrm{SiO}_{2} / \mathrm{Si}$. Transmittance values at $550 \mathrm{~nm}$ are $96.0 \%$ and $97.4 \%$ for $\mathrm{PMMA}$-coated and PMMA-removed samples, respectively. (e) $\mathrm{J}-V$ spectra of the devices with different structural colors measured under AM1.5, $100 \mathrm{~mW} \mathrm{~cm}^{-2}$. $J-V$ spectra of the devices without coating and with optimized anti-reflection coating were also presented for comparison. (a and c) Reproduced from ${ }^{104}$ with permission from The American Chemical Society. (b and e) Reproduced from ${ }^{87}$ with permission from Elsevier. (d) Reproduced from ${ }^{85}$ with permission from The Royal Society of Chemistry.

maximum refractive index nearly 2.5 while $\mathrm{MgF}_{2}$ owns the minimum refractive index of $1.4 .^{93,94}$ Therefore, the double layer $\mathrm{MgF}_{2} / \mathrm{ZnS}$ films can serve as efficient antireflection layers for solar cells. Meanwhile, they can enabled the graphene/Si solar cells with high color saturation. In this work, Ding et al. deposited $\mathrm{MgF}_{2} / \mathrm{ZnS}$ in sequence onto the graphene/Si solar cell by thermal evaporation. Different structural colors can be achieved by carefully tuning the thickness of the films. And the coated graphene/Si solar cells exhibited respectable power conversion efficiency in the range of 10.7-13.2\%. With 
a

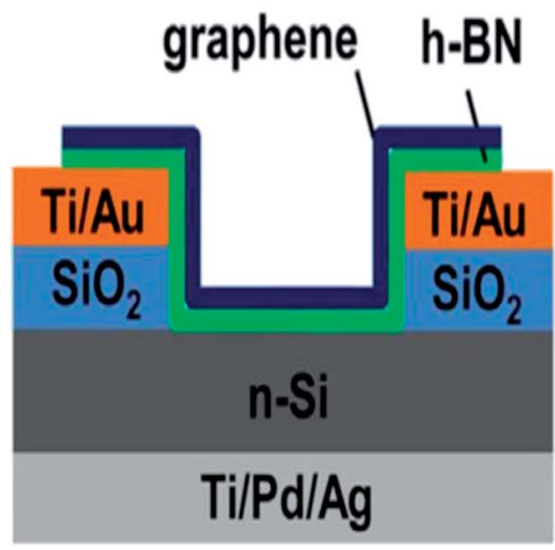

C

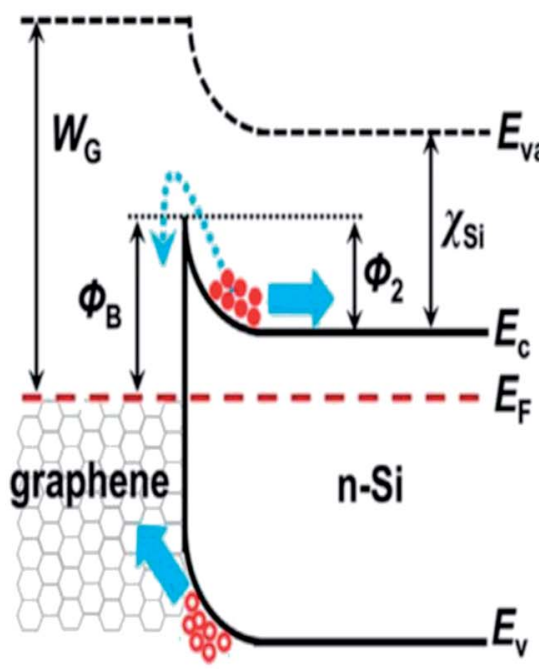

b
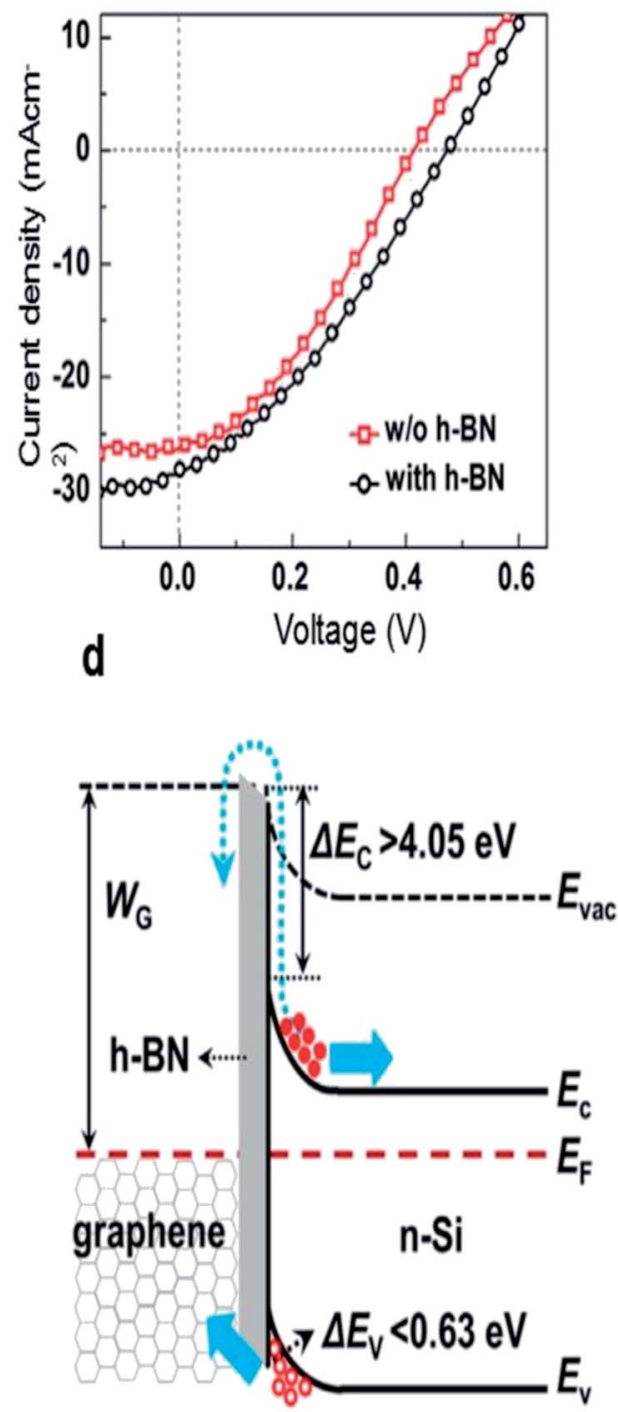

Fig. 8 (a) Schematic illustration of graphene/h-BN/Si solar cells. (b) Illuminated J-V characteristics of the graphene/Si solar cells with and without an h-BN interlayer. (c and d) Energy band diagrams of the graphene/Si Schottky junction solar cells without and with an h-BN electron blocking layer. Reproduced from ${ }^{58}$ with permission from Elsevier.

the optimized $\mathrm{MgF}_{2} / \mathrm{ZnS}$ antireflection coating, PCE of the device can reach up to $14.6 \%$ (Fig. 7e). Their work demonstrates the great potential to fabricate colorful graphene/Si solar cells for future high-efficiency, low-cost and designable PV panels.

\subsection{Interface engineering}

The PCE of the graphene/Si solar cells can reach up to $10 \%$ after reflectivity optimization of silicon, but the efficiency is still much lower than the commercial silicon solar cells based on $\mathrm{p}-\mathrm{n}$ junction, which is mainly restricted by the strong recombination of carriers along the interface due to the low barrier height. One solution to this problem is to introduce a passivation dielectric film between graphene and $\mathrm{Si}$, thereby forming a metal-insulator-semiconductor (MIS) structure. ${ }^{95,96}$
In a MIS solar cell, the additional insulating film can reduce the carrier recombination by suppressing diffusion of electrons from n-Si to graphene, and help the holes transfer to the graphene layer through tunnelling processes. Both mechanisms lead to improved $V_{\mathrm{OC}}$ and PCE of solar cells.

The best insulating layer materials include $\mathrm{SiO}_{2},{ }^{53,54} \mathrm{MoS}_{2},{ }^{55}$ $\mathrm{Al}_{2} \mathrm{O}_{3},{ }^{56}$ graphene oxide (GO), ${ }^{57} \mathrm{~h}-\mathrm{BN},{ }^{58}$ 3-hexylthiophene (P3HT) ${ }^{59}$ Several groups have demonstrated that the interface of the graphene/Si heterojunction play an important role in high efficient photoelectronic devices..$^{53-59}$

Song et al. inserted $\mathrm{SiO}_{2}$ as an electron blocking layer by exposing the substrate in air to allow the native oxide to regrow and layer thicknesses were optimized for achieving the best performance for graphene/Si solar cells. ${ }^{53}$ In the conventional Si wafer pretreatment, the native silicon oxide was usually 
completely etched before the graphene films were transferred. However, it has been demonstrated that leaving the silicon exposed to air for some time can allow a moderately thick oxide to regrow, ${ }^{97,98}$ yielding improved performance. To systematically study the effect of oxide thickness on the performance of the graphene/Si solar cells, the devices were left in air for varied duration before transferring graphene. The results showed that with the increasing oxide thickness from $5 \AA$ to $15 \AA$, the efficiency can be improved from $7.9 \%$ to $12.4 \% . V_{\mathrm{OC}}$ and $\mathrm{FF}$ were both improved further if the device left in air longer before transfer. For devices with $15 \AA$ oxide, $V_{\mathrm{OC}}$ increased to $0.59 \mathrm{~V}$ and the $\mathrm{FF}$ increased to 0.74 . Furthermore, $\mathrm{TiO}_{2}$ antireflective coating (ARC) and $\mathrm{AuCl}_{3}$ doping were also applied to the device, the overall efficiency can reach up to $15.6 \%$.

P3HT organic layer were introduced by Xie $e t$ al. and Zhang et al. as an interfacial layer, and in their work, P3HT was inserted into the graphene-Si interface as an electron blocking layer, preventing electrons diffusion from $\mathrm{n}$-Si to the graphene, minimizing the dark saturation current and a large leakage current. ${ }^{59} \mathrm{P} 3 \mathrm{HT}$ layer was spin-coated on $\mathrm{Si}$ within the window area and the thickness of the P3HT layer was carefully controlled by adjusting the solution concentration. With the increasing of the P3HT thickness, the PCE improved from $4.24 \%$ with $0 \mathrm{~nm}$-thick P3HT layer to $9.70 \%$ with a $10 \mathrm{~nm}$-thick P3HT layer. Further increase of the P3HT thickness to $40 \mathrm{~nm}$ would result in an obvious performance degradation. Supplemented with the by doping and optimization of the graphene layer number, a PCE of $10.56 \%$ was achieved.

Meng et al. introduced a few-layer h-BN between graphene and $\mathrm{n}$-Si to improve the performance of the solar cells. ${ }^{58}$ As shown in Fig. 8a, the few-layer h-BN and the CVD-grown few-layer graphene were successively transferred onto the patterned substrate by LBL transfer process. After introducing the h-BN layer, the $V_{\mathrm{OC}}$ and PCE were increased from 0.412 to $0.474 \mathrm{~V}$ and from $3.75 \%$ to $4.40 \%$, respectively in pristine cells (Fig. 8b). They explained that the h-BN can not only act as an effective electron-blocking/holetransporting layer, but also has suitable band alignment with $\mathrm{Si}$, and thus the interface recombination was suppressed and the open circuit voltage was significantly increased (Fig. $8 \mathrm{c}$ and d). In order to avoid the interface contamination and defects arising from the LBL process, they also transferred the directly grown graphene/h-BN heterostructure onto the graphene/h-BN/Si solar cell by one step method. ${ }^{99}$ A maximum efficiency of $10.93 \%$ was achieved for the graphene/h-BN/Si solar cells by combining the directly grown graphene/h-BN heterostructures with co-doping of graphene with Au nanoparticles and $\mathrm{HNO}_{3}$.

Ma et al. demonstrate the fabrication of high efficiency graphene/ $\mathrm{MoS}_{2} / \mathrm{Si}$ Schottky barrier solar cells with $\mathrm{MoS}_{2}$ interlayers. ${ }^{55}$ The inserted $\mathrm{MoS}_{2}$ layers function as hole transport layer to facilitate the separation of electron-hole pairs as well as electron blocking layer to suppress the recombination at graphene/silicon interfaces. By optimizing the thickness of $\mathrm{MoS}_{2}$ layers, a high photovoltaic conversion efficiency of $15.8 \%$ was achieved in graphene $/ \mathrm{MoS}_{2} / \mathrm{Si}$ solar cells, which is a new record reported so far.

\section{Conclusions, challenges and prospects}

In this article, we briefly reviewed the optimization approaches of the graphene/Si Schottky solar cells in recent years. These approaches could be categorized as optimization of (1) the work function and conductivity of graphene, (2) the reflectivity of silicon, (3) passivation and energy band engineering of the graphene/Si interface. Assisted with these approaches, the PCE has increased from $1.5 \%$ to $15.8 \%$ in less than a decade. In spite of the rapid progress in this field, there are still some issues need to be addressed.

(1) Till now, different approaches have been tried to improve the efficiency of the solar cells, such as chemical doping of graphene, passivation and band-engineering of the graphene/Si interface, introduction of antireflection layer or nano/ microstructures to improve the light harvest, the graphene layer number controlling. Among them, chemical doping has been recognized as the most effective method to optimize the performance of the solar cells. Although many doping dopants have been introduced, the stability of solar cells is still a serious challenge due to the instability of the doping methods. Cui et al. presented a significant high-stability single-walled carbon nanotube (SWNT)/Si solar cells with a PCE over $11 \%$ after 10 months of exposure to ambient conditions..$^{100} \mathrm{Jia}$ et al. demonstrated CNT (carbon nanotube)-oxide-Si cells with a PDMS antireflection layer, and the efficiency showed a slight drop from $10.9 \%$ to $9.1 \%$ for 20 days in air. ${ }^{101}$ Yang et al. reported a new structure of graphene-Si solar cells by introducing a graphene oxide (GO) interlayer to engineer the graphene-Si interface for improving device performance, the graphene/GO/Si solar cell retains $95 \%$ of its original level after storing in the open air for one week. ${ }^{102}$ Rehman et al. inserted an $\mathrm{Al}_{2} \mathrm{O}_{3}$ interlayer between the $\mathrm{Si}$ and graphene to suppress the surface charge recombination at the interface, and the efficiency of solar cell was not degraded after 9 months period exposed in ambient air. ${ }^{103}$ So, a high stability of materials such as carbon nanotube can be used for a long-term stability of the solar cell. In addition, exploring new structure of the solar cells, for example, introduce an interlayer to engineer a graphene-Si interface to form a metal insulator semiconductor (MIS) structure may also be an important direction in this field.

(2) The PCE of the graphene/Si solar cells has reached up to $15.8 \%$ in just a few years, but it is still lower than that of commercial Si p-n junction solar cells. Due to the limitation of low electrical conductivity and low work function of graphene, the active area of the solar cell is relatively small $\left(<10 \mathrm{~mm}^{2}\right)$ in current research. Xie et al. and Zhang et al. demonstrated the device performance with various device areas from 4 to 100 $\mathrm{mm}^{2}$, they found that with the increasing device area, the PCE decreased from $10.56 \%$ to $3.62 \%,{ }^{59}$ similarly, Shi et al. also reported that the PCE of graphene/Si solar cells decreased from $14.5 \%$ to $10.6 \%$ when the active area was increased from 4.7 $\mathrm{mm}^{2}$ to $14.5 \mathrm{~mm}^{2}{ }^{104}$ all these results show that there is a close relationship between the active area and PCE. With a larger size of active area, the collection efficient of photogenerated charge 
carriers would be lower because of the low conductivity of the graphene layer. In order the improve the conductivity of the graphene layer, Suhail et al. introduced with grid electrode to the conventional window-based device structure, ${ }^{\mathbf{1 0 5}}$ which could provide a low resistance contact to the graphene layer, and it might also help to improve the efficiency of carrier collection. So a fine metal electrode design should be adopted on the front to facilitate carrier collection through the entire device area.

(3) It is known that graphene is transferred on the $\mathrm{Si}$ substrate to form the Schottky junction, but graphene is easy to be cracked and torn, and copper particles residual may remain on the graphene film after the wet etching, ${ }^{\mathbf{9 1 , 1 0 6}}$ all the defects and impurities at the graphene/Si interface can serve as shortcircuit channels and lead to current leakage. Predictably, the current leakage will be more obvious at a larger device area. And large area of graphene is therefore a critical factor influencing the collection efficiency. In this regard, more matured production and transfer skills should be developed to decrease the defects and impurities arisen in the wet transfer process, and it is also a reliable method to grow graphene directly on semiconductor surface to get less structural defects and uniform film of graphene. ${ }^{107}$

\section{Conflicts of interest}

There are no conflicts to declare.

\section{Acknowledgements}

This project was supported by National Science Foundation of China (No. 11574014).

\section{References}

1 M. A. Green, Energy Policy, 2000, 28, 989-998.

2 S. Ashraf, R. Su, J. Akhtar, H. M. Siddiqi and A. El-Shafei, Dyes Pigm., 2018, 150, 347-353.

3 S. Mathew, A. Yella, P. Gao, R. Humphry-Baker, B. F. Curchod, N. Ashari-Astani, I. Tavernelli, U. Rothlisberger, M. K. Nazeeruddin and M. Gratzel, Nat. Chem., 2014, 6, 242-247.

4 W. S. Yang, B. W. Park, E. H. Jung, N. J. Jeon, Y. C. Kim, D. U. Lee, S. S. Shin, J. Seo, E. K. Kim, J. H. Noh and S. I. Seok, Science, 2017, 356, 1376-1379.

5 K. Yoshikawa, W. Yoshida, T. Irie, H. Kawasaki, K. Konishi, H. Ishibashi, T. Asatani, D. Adachi, M. Kanematsu, H. Uzu and K. Yamamoto, Sol. Energy Mater. Sol. Cells, 2017, 173, 37-42.

6 G. A. Kachurin, I. E. Tyschenko and L. I. Fedina, Nucl. Instrum. Methods Phys. Res., 1992, 68, 323-330.

7 T. Warabisako, T. Uematsu, S. Muramatsu, K. Tsutsui, H. Ohtsuka, Y. Nagata and M. Sakamoto, Sol. Energy Mater. Sol. Cells, 1997, 48, 137-143.

8 W. Di and K. Jani, Nanoscale, 2013, 5, 10108-10126.

9 Y. Ye, L. Dai, P. C. Wu, C. Liu, T. Sun, R. M. Ma and G. G. Qin, Nanotechnology, 2009, 20, 375202.
10 S. B. Photodiodes, Metal-semiconductor Schottky barrier junctions and their applications, Plenum Press, 1984.

11 D. W. Kim, Y. J. Sung, J. W. Park and G. Y. Yeom, Thin Solid Films, 2001, 398, 87-92.

12 J. Li, H. Chen and J. Xue, J. Photonics Energy, 2014, 4, 040990.

13 K. S. Novoselov, A. K. Geim, S. V. Morozov, D. Jiang, Y. Zhang, S. V. Dubonos, I. V. Grigorieva and A. A. Firsov, Science, 2004, 306, 666-669.

14 B. Partoens and F. M. Peeters, Phys. Rev. B: Condens. Matter Mater. Phys., 2006, 74, 075404.

15 L. A. Falkovsky, J. Phys.: Conf. Ser., 2008, 129, 012004.

16 R. R. Nair, P. Blake, A. N. Grigorenko, et al., Science, 2008, 320, 1308.

17 F. Bonaccorso, Z. Sun, T. Hasan and A. C. Ferrari, Nat. Photonics, 2010, 4, 611-622.

18 A. K. Geim and K. S. Novoselov, Nat. Mater., 2007, 6, 183191.

19 J. Wu, M. Agrawal, H. A. Becerril, Z. Bao, Z. Liu, Y. Chen and P. Peumans, ACS Nano, 2010, 4, 43-48.

20 T.-H. Han, Y. Lee, M.-R. Choi, S.-H. Woo, S.-H. Bae, B. H. Hong, J.-H. Ahn and T.-W. Lee, Nat. Photonics, 2012, 6, 105-110.

21 Z. Fan, B. Liu, X. Liu, Z. Li, H. Wang, S. Yang and J. Wang, Electrochim. Acta, 2013, 109, 602-608.

22 E. W. Hill, A. Vijayaragahvan and K. Novoselov, IEEE Sens. J., 2011, 11, 3161-3170.

23 X. Li, H. Zhu, K. Wang, A. Cao, J. Wei, C. Li, Y. Jia, Z. Li, X. Li and D. Wu, Adv. Mater., 2010, 22, 2743-2748.

24 X. Wang, A. Linjie Zhi and K. Müllen, Nano Lett., 2008, 8, 323.

25 K. S. Kim, Y. Zhao, H. Jang, S. Y. Lee, J. M. Kim, K. S. Kim, J. H. Ahn, P. Kim, J. Y. Choi and B. H. Hong, Nature, 2009, 457, 706-710.

26 Z. Liu, Q. Liu, Y. Huang, Y. Ma, S. Yin, X. Zhang, W. Sun and Y. Chen, Adv. Mater., 2008, 20, 3924-3930.

27 S. Bae, H. Kim, Y. Lee, X. Xu, J. S. Park, Y. Zheng, J. Balakrishnan, T. Lei, H. R. Kim, Y. I. Song, Y. J. Kim, K. S. Kim, B. Ozyilmaz, J. H. Ahn, B. H. Hong and S. Iijima, Nat. Nanotechnol., 2010, 5, 574-578.

28 S. Pang, Y. Hernandez, X. Feng and K. Mullen, Adv. Mater., 2011, 23, 2779-2795.

29 P. Avouris, Nano Lett., 2010, 10, 4285-4294.

30 Y. J. Yu, Y. Zhao, S. Ryu, L. E. Brus, K. S. Kim and P. Kim, Nano Lett., 2009, 9, 3430-3434.

31 W. Chen, S. Chen, D. C. Qi, X. Y. Gao and A. T. Wee, J. Am. Chem. Soc., 2007, 129, 10418-10422.

32 C. Lee, X. Wei, J. W. Kysar and J. Hone, Science, 2008, 321, 385-388.

33 Ç. Ö. Girit, J. C. Meyer, R. Erni, M. D. Rossell, C. Kisielowski, Y. Li, C. H. Park, M. F. Crommie, M. L. Cohen and S. G. Louie, Science, 2009, 323, 1705-1708.

34 G. Fiori, F. Bonaccorso, G. Iannaccone, T. Palacios, D. Neumaier, A. Seabaugh, S. K. Banerjee and L. Colombo, Nat. Nanotechnol., 2014, 9, 768-779. 
35 X. Wang, H. You, F. Liu, M. Li, L. Wan, S. Li, Q. Li, Y. Xu, R. Tian, Z. Yu, D. Xiang and J. Cheng, Chem. Vap. Deposition, 2009, 15, 53-56.

36 A. Di Bartolomeo, Phys. Rep., 2016, 606, 1-58.

37 M.-Y. Li, C.-H. Chen, Y. Shi and L.-J. Li, Mater. Today, 2016, 19, 322-335.

38 H. Zhong, K. Xu, Z. Liu, G. Xu, L. Shi, Y. Fan, J. Wang, G. Ren and H. Yang, J. Appl. Phys., 2014, 115, 013701.

39 S. M. Sze, IEEE J. Quantum Electron., 1981, 15, 1438.

40 D. Sinha and J. U. Lee, Nano Lett., 2014, 14, 4660-4664.

41 H. Yang, J. Heo, S. Park, H. J. Song, D. H. Seo, K. E. Byun, P. Kim, I. Yoo, H. J. Chung and K. Kim, Science, 2012, 336, 1140.

42 S. Tongay, M. Lemaitre, X. Miao, B. Gila, B. R. Appleton and A. F. Hebard, Phys. Rev. X, 2012, 2, 011002.

43 Y. Lin, X. Li, D. Xie, T. Feng, Y. Chen, R. Song, H. Tian, T. Ren, M. Zhong, K. Wang and H. Zhu, Energy Environ. Sci., 2013, 6, 108-115.

44 E. Shi, L. Zhang, Z. Li, P. Li, Y. Shang, Y. Jia, J. Wei, K. Wang, H. Zhu, D. Wu, S. Zhang and A. Cao, Sci. Rep., 2012, 2, 884.

45 X. Miao, S. Tongay, M. K. Petterson, K. Berke, A. G. Rinzler, B. R. Appleton and A. F. Hebard, Nano Lett., 2012, 12, 27452750.

46 X. Li, D. Xie, H. Park, M. Zhu, T. H. Zeng, K. Wang, J. Wei, D. Wu, J. Kong and H. Zhu, Nanoscale, 2013, 5, 1945-1948.

47 T. Feng, D. Xie, Y. Lin, H. Zhao, Y. Chen, H. Tian, T. Ren, X. Li, Z. Li, K. Wang, D. Wu and H. Zhu, Nanoscale, 2012, 4, 2130-2133.

48 T. Cui, R. Lv, Z.-H. Huang, S. Chen, Z. Zhang, X. Gan, Y. Jia, X. Li, K. Wang, D. Wu and F. Kang, J. Mater. Chem. A, 2013, 1, 5736.

49 X. Liu, X. W. Zhang, Z. G. Yin, J. H. Meng, H. L. Gao, L. Q. Zhang, Y. J. Zhao and H. L. Wang, Appl. Phys. Lett., 2014, 105, 183901.

50 Y. Jia, A. Cao, X. Bai, Z. Li, L. Zhang, N. Guo, J. Wei, K. Wang, H. Zhu, D. Wu and P. M. Ajayan, Nano Lett., 2011, 11, 1901-1905.

51 Y. F. Li, W. Yang, Z. Q. Tu, Z. C. Liu, F. Yang, L. Q. Zhang and R. Hatakeyama, Appl. Phys. Lett., 2014, 104, 043903.

52 K. Ihm, J. T. Lim, K.-J. Lee, J. W. Kwon, T.-H. Kang, S. Chung, S. Bae, J. H. Kim, B. H. Hong and G. Y. Yeom, Appl. Phys. Lett., 2010, 97, 032113.

53 Y. Song, X. Li, C. Mackin, X. Zhang, W. Fang, T. Palacios, H. Zhu and J. Kong, Nano Lett., 2015, 15, 2104-2110.

54 Y. Jia, P. Li, X. Gui, J. Wei, K. Wang, H. Zhu, D. Wu, L. Zhang, A. Cao and Y. Xu, Appl. Phys. Lett., 2011, 98, 133115.

55 J. Ma, H. Bai, W. Zhao, Y. Yuan and K. Zhang, Sol. Energy, 2018, 160, 76-84.

56 M. A. Rehman, I. Akhtar, W. Choi, K. Akbar, A. Farooq, S. Hussain, M. A. Shehzad, S.-H. Chun, J. Jung and Y. Seo, Carbon, 2018, 132, 157-164.

57 L. Yang, X. Yu, M. Xu, H. Chen and D. Yang, J. Mater. Chem. A, 2014, 2, 16877-16883.

58 J.-H. Meng, X. Liu, X.-W. Zhang, Y. Zhang, H.-L. Wang, Z.-G. Yin, Y.-Z. Zhang, H. Liu, J.-B. You and H. Yan, Nano Energy, 2016, 28, 44-50.
59 C. Xie, X. Zhang, Y. Wu, X. Zhang, X. Zhang, Y. Wang, W. Zhang, P. Gao, Y. Han and J. Jie, J. Mater. Chem. A, 2013, 1, 8567.

60 X. Liu, X. W. Zhang, J. H. Meng, Z. G. Yin, L. Q. Zhang, H. L. Wang and J. L. Wu, Appl. Phys. Lett., 2015, 106, 233901.

61 K. K. Kim, A. Reina, Y. Shi, H. Park, L. J. Li, Y. H. Lee and J. Kong, Nanotechnology, 2010, 21, 285205.

62 Y. C. Lai, B. S. Wu, S. C. Yu, P. C. Yu and G. C. Chi, in 2013 Ieee 39th Photovoltaic Specialists Conference, 2013, pp. 24362438.

63 Z. Kang, X. Tan, X. Li, T. Xiao, L. Zhang, J. Lao, X. Li, S. Cheng, D. Xie and H. Zhu, Phys. Chem. Chem. Phys., 2016, 18, 1992-1997.

64 J. H. Kim, D. H. Shin, H. S. Lee, C. W. Jang, J. M. Kim, S. W. Seo, S. Kim and S.-H. Choi, J. Mater. Chem. C, 2017, 5, 9005-9011.

65 X. Liu, X. W. Zhang, J. H. Meng, H. L. Wang, Z. G. Yin, J. L. Wu and H. L. Gao, Nanotechnology, 2014, 25, 365602.

66 T. Jiao, D. Wei, X. Song, T. Sun, J. Yang, L. Yu, Y. Feng, W. Sun, W. Wei, H. Shi, C. Hu and C. Du, RSC Adv., 2016, 6, 10175-10179.

67 Y. Wang, S. W. Tong, X. F. Xu, B. Ozyilmaz and K. P. Loh, Adv. Mater., 2011, 23, 1514-1518.

68 J. Kang, D. Shin, S. Bae and B. H. Hong, Nanoscale, 2012, 4, 5527-5537.

69 C.-H. Sun, P. Jiang and B. Jiang, Appl. Phys. Lett., 2008, 92, 061112.

70 Y. Zeng, X. Fan, J. Chen, S. He, Z. Yi, X. Ye and Y. Yi, Superlattices Microstruct., 2018, 117, 144-154.

71 T. Aho, M. Guina, F. Elsehrawy, F. Cappelluti, M. Raappana, A. Tukiainen, A. Alam, I. Vartiainen, M. Kuittinen and T. Niemi, Opt. Express, 2018, 26, A331-A340.

72 H. Dai, J. Sun, Z. Li, X. Yu, J. Zhao, H. Fang and Z. Zhu, Trans. Indian Inst. Met., 2018, 71, 1681-1686.

73 X. Jiang, P. Zhang, J. Zhang, J. Wang, G. Li, X. Fang, L. Yang and X. Chen, Nanoscale Res. Lett., 2018, 13, 53.

74 H. C. Chen, C. C. Lin, H. W. Han, Y. L. Tsai, C. H. Chang, H. W. Wang, M. A. Tsai, H. C. Kuo and P. Yu, Opt. Express, 2011, 19(suppl 5), A1141.

75 T. Feng, D. Xie, Y. Lin, Y. Zang, T. Ren, R. Song, H. Zhao, H. Tian, X. Li, H. Zhu and L. Liu, Appl. Phys. Lett., 2011, 99, 233505.

76 J.-T. Lin, C.-C. Lai, C.-T. Lee, Y.-Y. Hu, K.-Y. Ho and S. W. Haga, IEEE J. Photovolt., 2018, 8, 669-675.

77 E. Garnett and P. Yang, Nano Lett., 2010, 10, 1082.

78 E. C. Garnett and P. Yang, J. Am. Chem. Soc., 2008, 130, 9224-9225.

79 S. K. Srivastava, D. Kumar, S. W. Schmitt, K. N. Sood, S. H. Christiansen and P. K. Singh, Nanotechnology, 2014, 25, 175601.

80 H. Jansen, M. De Boer, R. Legtenberg and M. Elwenspoek, J. Micromech. Microeng., 1999, 5, 115-120.

81 G. Fan, H. Zhu, K. Wang, J. Wei, X. Li, Q. Shu, N. Guo and D. Wu, ACS Appl. Mater. Interfaces, 2011, 3, 721-725.

82 Y. P. Hsu, S. J. Chang, Y. K. Su, J. K. Sheu, C. H. Kuo, C. S. Chang and S. C. Shei, Opt. Mater., 2005, 27, 1171-1174. 
83 H. Jansen, M. D. Boer, H. Wensink, B. Kloeck and M. Elwenspoek, Microelectron. J., 2001, 32, 769-777.

84 C. Xie, X. Zhang, K. Ruan, Z. Shao, S. S. Dhaliwal, L. Wang, Q. Zhang, X. Zhang and J. Jie, J. Mater. Chem. A, 2013, 1, 15348.

85 X. Gan, R. Lv, H. Zhu, L.-P. Ma, X. Wang, Z. Zhang, Z.-H. Huang, H. Zhu, W. Ren, M. Terrones and F. Kang, J. Mater. Chem. A, 2016, 4, 13795-13802.

86 X. Zhang, H. Ye, B. Xiao, L. Yan, H. Lv and B. Jiang, J. Phys. Chem. C, 2010, 114, 19979-19983.

87 K. Ding, X. Zhang, L. Ning, Z. Shao, P. Xiao, A. Ho-Baillie, X. Zhang and J. Jie, Nano Energy, 2018, 46, 257-265.

88 L. Lancellotti, E. Bobeico, A. Castaldo, P. Delli Veneri, E. Lago and N. Lisi, Thin Solid Films, 2018, 646, 21-27.

89 H. K. Raut, V. A. Ganesh, A. S. Nair and S. Ramakrishna, Energy Environ. Sci., 2011, 4, 3779.

90 R. B. Pettit, C. J. Brinker and C. S. Ashley, Sol. Cells, 1985, 15, 267-278.

91 X. Liang, B. A. Sperling, I. Calizo, G. Cheng, C. A. Hacker, Q. Zhang, Y. Obeng, K. Yan, H. Peng and Q. Li, ACS Nano, 2011, 5, 9144-9153.

92 X. Li, Y. Zhu, W. Cai, M. Borysiak, B. Han, D. Chen, R. D. Piner, L. Colombo and R. S. Ruoff, Nano Lett., 2009, 9, 4359.

93 G. R. Olbright, N. Peyghambarian, H. M. Gibbs, H. A. Macleod and F. Van Milligen, Appl. Phys. Lett., 1984, 45, 1031-1033.

94 Z. Chen, P. Sana, J. Salami and A. Rohatgi, IEEE Trans. Electron Devices, 2002, 40, 1161-1165.
95 J. Bae, H. Kim, X. M. Zhang, C. H. Dang, Y. Zhang, Y. J. Choi, A. Nurmikko and Z. L. Wang, Nanotechnology, 2010, 21, 095502.

96 C. H. Lin, Nanoscale Res. Lett., 2012, 7, 343.

97 M. Morita, T. Ohmi, E. Hasegawa, M. Kawakami and M. Ohwada, J. Appl. Phys., 1990, 68, 1272-1281.

98 M. Morita, T. Ohmi, E. Hasegawa, M. Kawakami and K. Suma, Appl. Phys. Lett., 1989, 55, 562-564.

99 J. H. Meng, X. W. Zhang, H. L. Wang, X. B. Ren, C. H. Jin, Z. G. Yin, X. Liu and H. Liu, Nanoscale, 2015, 7, 1604616053.

100 K. Cui, A. S. Anisimov, T. Chiba, S. Fujii, H. Kataura, A. G. Nasibulin, S. Chiashi, E. I. Kauppinen and S. Maruyama, J. Mater. Chem. A, 2014, 2, 11311-11318.

101 Y. Jia, P. Li, X. Gui, J. Wei, K. Wang, H. Zhu, D. Wu, L. Zhang, A. Cao and Y. Xu, Appl. Phys. Lett., 2011, 98, 239. 102 L. Yang, X. Yu, M. Xu, H. Chen and D. Yang, J. Mater. Chem. A, 2014, 2, 16877-16883.

103 M. A. Rehman, I. Akhtar, W. Choi, K. Akbar, A. Farooq, S. Hussain, M. A. Shehzad, S. H. Chun, J. Jung and Y. Seo, Carbon, 2018, 132, 157-164.

104 E. Shi, H. Li, L. Yang, L. Zhang, Z. Li, P. Li, Y. Shang, S. Wu, X. Li, J. Wei, K. Wang, H. Zhu, D. Wu, Y. Fang and A. Cao, Nano Lett., 2013, 13, 1776-1781.

105 A. Suhail, G. Pan, D. Jenkins and K. Islam, Carbon, 2018, 129, 520-526.

106 M. Her, R. Beams and L. Novotny, Phys. Lett. A, 2013, 377, 1455-1458.

107 M. F. Bhopal, K. Akbar, M. A. Rehman, D. w. Lee, A. u. Rehman, Y. Seo, S.-H. Chun and S. H. Lee, Carbon, 2017, 125, 56-62. 